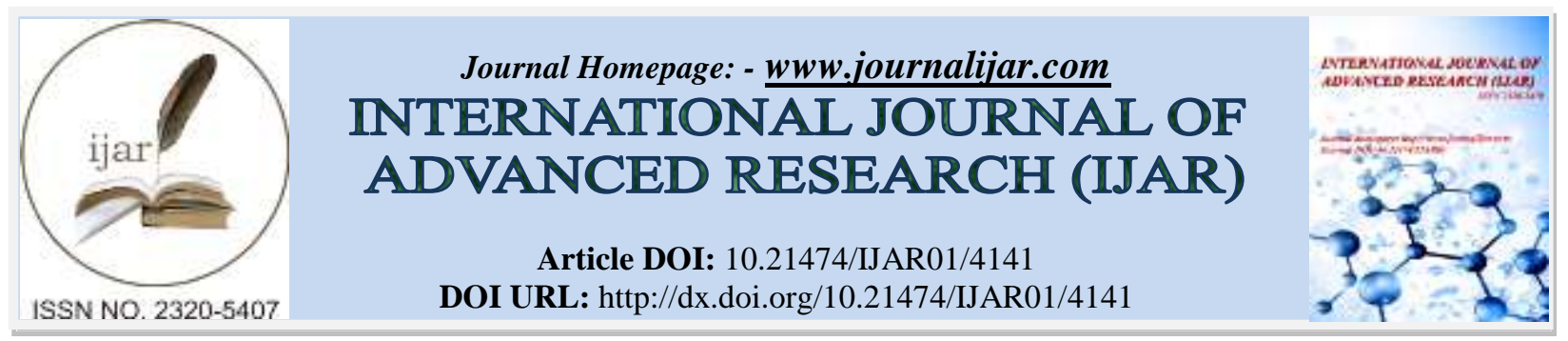

RESEARCH ARTICLE

\title{
ASYMPTOMATIC BACTERIURIA IN NORMAL PREGNANCY.
}

Tamar Didbaridze $^{1}$, Aleksandre Tharashvili ${ }^{2}$, Nino Gogokhia ${ }^{3}$, Nato Metskhvarishvili ${ }^{4}$ and Maia Rizhvadze ${ }^{5}$. 1. Microbiologist, TSMU The First University Clinic, MD, PhD (Tbilisi, Georgia).

2. Head of Department of Obstetrics and Gynecology, TSMU Professor (Tbilisi, Georgia).

3. Head of clinical laboratory, TSMU The First University Clinic, MD, $\mathrm{PhD}$ (Tbilisi, Georgia).

4. TSMU Department of Obstetrics and Gynecology, Assistant professor, MD, PhD(Tbilisi, Georgia).

5. TSMU Department of Obstetrics and Gynecology, MD, PhD,(Tbilisi, Georgia).

\section{Manuscript Info}

Manuscript History

Received: 04 March 2017

Final Accepted: 04 April 2017

Published: May 2017

Key words:-

Asymptomatic bacteriuria, pregnancy, urine.

\begin{abstract}
The prevalence of asymptomatic bacteriuria (ASB) in pregnant women is $2 \%$ to $10 \%$ and depends on race, parity, and socioeconomic status . Escherichia coli is the most common etiologic agent in asymptomatic infection and quantitative culture is the gold standard for diagnosis.In pregnant women this infection can progress upward, causing acute urethritis, acute cystitis(40\%), and acute pyelonephritis (25-30\%). Pyelonephritis, in turn, can lead to adverse outcomes such as preterm labor, which is the most common cause of serious complicationsincluding death-in newborn babies. A positive urine culture is the only means of diagnosis. The U.S. preventive service task force and American Congress of Obstetricians and Gynecologists most strongly recommend screening and treating for asymptomatic bacteriuria (ASB) in pregnant women.

We retrospectively have studied frequency and microbial spectrum of asymptomatic bacteriuria in pregnant women without clinical demonstrations with gestational age of 12-16 weeks who visited TSMU The First University Clinic obstetrics and gynecology department in 2015-2016 .Our results showed that the prevalence of asymptomatic bacteriuria in normal pregnant women is $9.3 \%$, which is approximately the same as the other countries(2-10\%). However, more studies are required to determine the specific rate of asymptomatic bacteriuria and factors that are responsible for region differences. Escherichia coli was the most common isolate accounting for approximately $53,8 \%$ of cases. It originates from fecal flora colonizing the per urethral area, causing an ascending infection.
\end{abstract}

Copy Right, IJAR, 2017,. All rights reserved.

\section{Introduction:-}

"Asymptomatic bacteriuria" is the presence of more than 100,000 organisms/ml in urine samples in the absence of declared symptoms. Asymptomatic bacteriuria is common in pregnant women. The prevalence of asymptomatic bacteriuria (ASB) in pregnant women is $2 \%$ to $10 \%$ and depends on race, parity, and socioeconomic status. Escherichia coli is the most common etiologic agent in asymptomatic infection and quantitative culture is the gold standard for diagnosis(1,2). Treatment of asymptomatic bacteriuria has been shown to reduce the rate of 
pyelonephritis in pregnancy and therefore screening for and treatment of asymptomatic bacteriuria has become a standard of obstetrical care. In pregnant women this infection can progress upward, causing acute urethriti, acute cystitis (40\%), and acute pyelonephritis (25-30\%). Pyelonephritis, in turn, can lead to adverse outcomes such as preterm labor, which is the most common cause of serious complications-including death -in newborn babies(3,4,5). A kidney infection can also lead to sepsis (pathogenic organisms or toxins invading the blood or tissue) and adult respiratory distress syndrome (ARDS)-both can be life threatening. Approximately 25 to 30 percent of asymptomatic bacteriuria cases in pregnancy will progress to symptomatic infection, three to four times as great a progression as in non-pregnant women. A positive urine culture is the only means of diagnosis $(6,7)$.

The anatomic and physiologic changes during pregnancy increase a woman's susceptibility to UTI and pyelonephritis. The progesterone induces dilation of the renal pelvis and ureter, the decreased peristalsis of the ureters, the mechanical obstruction from the enlarging uterus, and the increased bladder capacity resulted in urinary stasis. Along with the change in urine $\mathrm{pH}$ and osmolality, glucosuria and aminoaciduria also facilitate bacterial growth and thus progression to pyelonephritis $(8,9)$.

The U.S. preventive service task force and American Congress of Obstetricians and Gynecologists most strongly recommend screening and treating for asymptomatic bacteriuria (ASB) in pregnant women. The gold standard for ASB screening in pregnancy is the urine culture. A midstream clean catch urine specimen should be collected for screening culture at 12 to 16 weeks' gestation or at the first prenatal visit, if later. The presence of at least $10^{5}$ colony-forming units per $\mathrm{mL}(\mathrm{CFU} / \mathrm{mL})$ of urine with a single uropathogen is considered a positive test result. The benefits of early detection and treatment of ASB with antibiotics significantly reduce the incidence of symptomatic UTI and low birth weight $(10,11,12)$.

We retrospectively have studied frequency and microbial spectrum of asymptomatic bacteriuria in normal pregnant women who visited TSMU The First University Clinic obstetrics and gynecology department in 20152016.

\section{Material and Methods:-}

Urine cultures were performed for 140 pregnant women without clinical demonstrations with gestational age of 12 16 weeks. Midstream portion of morning urine were carefully collected in sterile plastic containers and sent for culture to the lab. Bacteriological research covered: streaking by calibrated inoculating loops $0,001 \mathrm{ml}$ on differencial,selective and chromogenic agar(uriSelect4, Bio-Rad Laboratores), isolation of poor culture,Gram stain, identification of microbes with rapid identification system (API20E, API Staph, API Strep20, bioMerieux). Also rapid tests defining oxidase and catalase and simultiously dip slides(Thermo Fisher) were also used. After 24-48 hour incubation at $37^{\circ} \mathrm{C}$ :no growth indicates that there is no infection, however, a urine culture we repeated on another sample to look for the presence of bacteria at lower colony counts . The presence of at least $10^{5}$ colonyforming units per $\mathrm{mL}(\mathrm{CFU} / \mathrm{mL})$ of urine with a single uropathogen was considered a positive test result and susceptibility testing by Kirby Bauer disk diffusion method was performed to guide treatment.

\section{Results:-}

Among researched in 13 patients(9.3\%) was monomicrobial growth by bacteriological research :Escherichia coli 7 cases $(53,8 \%)$,Enterobacter cloacae -1(7,6\%), Staphilococcus aureus was isolated in 3 cases(23.0\%), Enterococcus faecalis $-2(15,4 \%)$. Polymicrobial growth was not observed. Negative culture was in 127 patients(90,7\%) .No significant difference was found in positive cultures with mother's age, educational level, and history of pregnancy.

\section{Conclusion:-}

Our results showed that the prevalence of asymptomatic bacteriuria in normal pregnant women is $9.3 \%$, which is approximately the same as the other countries(2-10\%). However, more studies are required to determine the specific rate of asymptomatic bacteriuria and factors that are resposible for region differences. Escherichia coli was the most common isolate accounting for approximately 53,8\% of cases. It originates from fecal flora colonizing the periurethral area, causing an ascending infection. 


\section{References:-}

1. Hooton TM, Roberts PL, Cox ME, Stapleton AE. Voided midstream urine culture and acute cystitis in premenopausal women. N Engl J Med 2013;

2. Widmer M, Lopez I, Gülmezoglu AM, et al. Duration of treatment for asymptomatic bacteriuria during pregnancy. Cochrane Database Syst Rev 2015;

3. Hooton TM, Roberts PL, Cox ME, Stapleton AE. Voided midstream urine culture and acute cystitis in premenopausal women. N Engl J Med 2013; 369:1883.

4. Gupta K, Hooton TM, Naber KG, et al. International clinical practice guidelines for the treatment of acute uncomplicated cystitis and pyelonephritis in women: A 2010 update by the Infectious Diseases Society of America and the European Society for Microbiology and Infectious Diseases. Clin Infect Dis 2011; 52:e103.

5. Vazquez JC, Abalos E. Treatments for symptomatic urinary tract infections during pregnancy. Cochrane Database Syst Rev 2011; :CD002256.

6. Gomi H, Goto Y, Laopaiboon M, et al. Routine blood cultures in the management of pyelonephritis in pregnancy for improving outcomes. Cochrane Database Syst Rev 2015; :CD009216.

7. Albright $\mathrm{CM}$, Ali TN, Lopes $\mathrm{V}$, et al. Lactic acid measurement to identify risk of morbidity from sepsis in pregnancy. Am J Perinatol 2015; 32:481.

8. Keating GM. Fosfomycintrometamol: a review of its use as a single-dose oral treatment for patients with acute lower urinary tract infections and pregnant women with asymptomatic bacteriuria. Drugs 2013; 73:1951.

9. Urinary Tract Infection". CDC. April 17, 2015. Retrieved 9 February 2016.

10. Flores-Mireles, AL; Walker, JN; Caparon, M; Hultgren, SJ (May 2015).

11. Goldstein, I; Dicks, B; Kim, NN; Hartzell, R (December 2013). "Multidisciplinary overview of vaginal atrophy and associated genitourinary symptoms in postmenopausal women.". Sexual medicine. 1 (2):

12. Colgan, R; Nicolle, LE; McGlone, A; Hooton, TM (Sep 15, 2006). "Asymptomatic bacteriuria in adults.". American family physician. 74 (6): 985-9. 